\title{
Molecular Docking Studies of Bioactive Compounds from Solenostemma Argel Leaf Extract as Potential Inhibitor for BCL-2 Antiapoptotic Proteins
}

\author{
Mehad Mustafa Adam Khamiss ${ }^{1}$ \\ ${ }^{1}$ Department of Chemistry, \\ Faculty of Science, Mewar University, \\ Gangrar, Chittorgarh (Raj.) INDIA
}

\begin{abstract}
This article deals with anticancer studies of phytochemicals identified from Solenostemma Argel leaf extract using GC-MS analysis and molecular docking studies. B cell lymphoma-2 (BCL-2) agonists are useful for regulating apoptosis which is essential for several cancers. The aim of the present study is to investigate the $\mathrm{BCl}-2$ agonist property of phytochemicals from the extract of $S$. Argel using an Insilco approach. The docking on human BCL-2 protein was determined by GOLD 3.0.1 software. It is concluded from the studies that compound suggested by GCMS at RT 17.1 minute is 4,5,7-trihydroxy isoflavone showed best result with highest fitness index.
\end{abstract}

Keywords:- Cancer; Docking studies; BCL-2; Solenostemma argel

\section{INTRODUCTION}

Cancer is usually known as uncontrolled growth of abnormal cells in the body [1] and it occurs due to abnormalities in the DNA sequence [2]. Epidemiological studies are summarized as various parameters, to peep inside the etiology of cancer sach as geo-location, gender, age, ethnicity and trans-migrators along together disclosed that the factor which influences cancer more is lifestyle [35]. In today's environmental scenario pollution from automobile exhaust, solar radiation, professional submission to cancerous chemicals and mutagens, some specific bacterial or viral infections and hereditary sensitivity also increases the risk intensity of having cancer [ 6-7]. Healthy lifestyle which includes non-smoking, nonalcohol intake, more physical activity, healthy and balanced diet have positive influence on reducing cancer risk [8]. B cell lymphoma-2 (Bcl-2) belongs to a family of protein containing antiapoptotic, proapoptotic activators and a proapoptotic effector that affects certain mechanisms to function [9]. While apoptosis, activists such as tBid, Puma and Bim, bind antiapoptotic proteins and proapoptotic Bcl2 [10]. Active proteins including Bad, Noxa, Bik, Hrk, Bnip3 and Bmf, release antibodies to antiapoptotic proteins (ie Bcl-2, Bcl-w, Bcl-XL, Mcl-1 and A1), respectively. Method initiates the formation of the external mitochondrial membrane, liberating biomarker similar to cytochrome $\mathrm{c}$ and apoptosis causing factor [11-13]. Thereafter, this process leads to the development of apoptotic mechanism. Non-invasive apoptosis is important in the development of cancer. The apoptotic procedure is

\author{
Prakash C. Choudhary* \\ * Department of Chemistry, \\ Faculty of Science, Mewar University, Gangrar, Chittorgarh
} (Raj.) INDIA

severely restricted from direct interaction with the members of the antiapoptotic protein; these proteins bind and sequester promoters from interacting effectors, thereby directly preventing effectors from using MOMP [14]. Excessive expression of Bcl-2 antiapoptotic protein has been found to intercept chemo-drug-inspired apoptosis in diverse cancers [15]. The ability of these proteins to inhibit apoptosis has found feed in the growth of cancer drugs. Bcl-2 antiapoptotic proteins having $\mathrm{BH} 1, \mathrm{BH} 2$ and $\mathrm{BH} 3$ domains by forming a hydrophobic region on that binds to a protein-protein interaction involving the $\mathrm{Bcl}-2$ protein family [16]. Interference with this receptor suppresses the antiapoptotic activity of the protein components, demonstrating its strength. i.e. synthetic peptides interacting with the hydrophobic package of $\mathrm{Bcl}-2$ proteins have been manifested to cause apoptosis in vitro [17]. Although many drugs are prepared to target, members of the Bcl-2 antiapoptotic protein in recent years but they found unable to produce beneficial clinical results [18].

Information on epidemiological data showed that dietary habits have an impact on cancer risk. Taking care of these ideologies, a great scientific interest has been developed in developing a variety of dietary strategies [1920]. This plant Solenostemma argel is used from centuries in Sudan and its nearby places for dietary supplement and to cure diseases like cough, cold, fever and others as herbal medicine also. So we selected this Sudanese tribal herb for our studies to identify its cancer preventive efficacy and associated molecular mechanisms.

\section{METHODOLOGY}

\section{A. GC-MS method for identification of compounds}

GC-MS analysis was performed by GC CLARUS 550 PerkinElmer system containing a gas chromatography mass spectrometer (GC-MS) using: column Elite-1 capillary column $(30 \times 0.25 \mathrm{~mm} \mathrm{ID} \times 1 \mathrm{EM} \mathrm{df}$, at $70 \mathrm{eV}$ electron impact mode; extra pure helium gas was used at flow rate of $1 \mathrm{ml} / \mathrm{min}$ with constant flow as a carrier gas with $0.5 \mathrm{EI}$ injection volume (calculated with split ratio of 10: 1); injector temperature $250^{\circ} \mathrm{C}$; ion source temperature $280^{\circ}$ C. The oven temperature started from $110^{\circ} \mathrm{C}$, with an increase of $10^{\circ} \mathrm{C} / \mathrm{min}$. to $200^{\circ} \mathrm{C}$, and after achiving it, $5^{\circ}$ $\mathrm{C} / \mathrm{min}$ up to $280^{\circ} \mathrm{C}$. Mass spectra were taken at $0.5 \mathrm{sec}$ scan time with fragment from 40 to $550 \mathrm{Da}$. 


\section{B. Structure Prediction:}

The structure of BCL-2 was found in the PDB database. SPDBV software was used for removal of unnecessary chains and heteroatoms, and again hydrogen atoms were added to the protein identifies the operative site.

\section{Active site Identification}

The active BCL-2 site of Homosapiens was spotted out using the CASTp server. It was also used for detecting and calculating packets of proteins and holes, comprising alpha shape and discrete flow theory. CASTp recognizes and calculates pockets and pocket mouth openings, also holes. The program describes pockets atoms, binding pocket openings, and covered holes (cavities), volume and area of pocket and cavities and the edges of the mouth opening.

\section{Docking method}

Docking was performed by GOLD (Genetic Optimization of Ligand Docking) software which is working on the genetic algorithm (GA). This method allows partial flexibility of protein and complete ligand flexibility. The target molecules identified in GC-MS were docked in the active site of BCL-2 of Homo sapiens. Caffeine interactions with active site residues were well deliberated employing molecular mechanism estimations. Specifications used for GA were population size (100), selection pressure (1.1), operating value $(10,000)$, island value (1) and niche size (2). The operator specifications for crossover mutation and migration are set to 1000,100 and 10 respectively. The default cutoff values of $3.0 \mathrm{~A}^{\circ}(\mathrm{dH}-\mathrm{X})$ for hydrogen bond and $6.0 \mathrm{~A}^{\circ}$ for vanderwaal bonds were applied. The default algorithm speed was taken and the ligand binding area in the target was fixed at $10 \mathrm{~A}^{\circ}$ radius and centroid as the $\mathrm{CE}$ atom of active residues. During docking process, 100 poses for every inhibitor was set, and discontinuation was permitted if the maximum ligandbinding match was $1.5 \mathrm{~A}^{\circ}$ RMSD. After docking, the discrete binding cavities for compounds and interaction with protein were calculated. The finest energy favored symmetry of ligand was chosen.

\section{E. Gold Score fitness function:}

A force field scoring function is performed in Gold Score. It has four constituents: 1. Protein-ligand hydrogen bond energy (external H-bond); 2. Protein-ligand vander Waals energy (external vdw); 3.Ligand internal vander Waals energy (internal vdw); 4.Ligand intramolecular hydrogen bond energy (internal- $\mathrm{H}$ - bond). For the calculation of total fitness score, a factor of 1.375 is multiplied with external vdw score. This modification is designed to promote hydrophobic protein-ligand interactions. The fitness function is prepared for the projection of binding ligand sites.

Gold Gold $=S$ (hb_ext $)+S($ vdw_ext $)+S\left(h b \_i n t\right)+S$ (vdw_int)

Here in this equation $\mathrm{S}$ (hb_ext is protein-ligand hydrogen bond, S (vdw_ext) points for protein-ligand van der Waals, S (hb_int) stands for intramolecular hydrogen bond to ligand and S (vdw_int) is the intramolecular strain to the ligand [21].

\section{RESULTS AND DISCUSSION}

To get the final stable Bcl-2 structure, the PDB data base was used as shown in figure 1 . The heteroatoms were used to remove the ligands attached to the structure which are not useful and making overcrowding in the crystal structure for docking purpose.

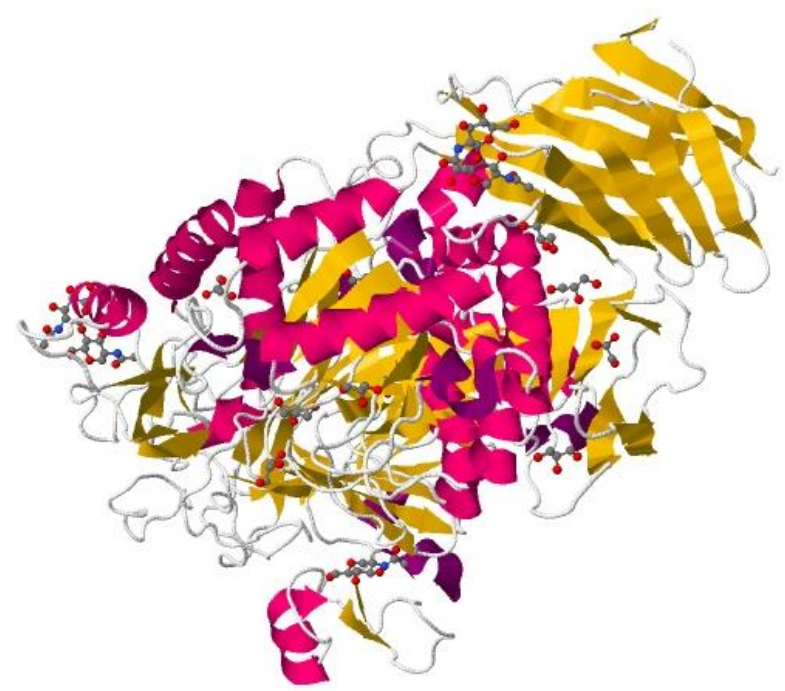

Fig 1:- Structure of BCL-2

\section{A. GC-MS Compound identification:}

The GCMS analysis showed different compounds at different retention Time (RT) which are mentioned below in table 01 . Out of these compounds, the most structurally stable compounds were subjected for docking studies. 


\begin{tabular}{|c|c|c|}
\hline S. No. & $\begin{array}{c}\text { Retention Time } \\
\text { in } \\
\text { GC-MS }\end{array}$ & $\begin{array}{l}\text { Supposed Comp. by } \\
\text { GC-MS Library }\end{array}$ \\
\hline 1 & 10.77 & Cyclohexane,1ethenyl-1-methyl-2,4-bis(1-methylethenyl)- \\
\hline 2 & 12.5 & 6-(3-isopropylcycloprop-1-enyl)-6-methylhept-3-en-2-one \\
\hline 3 & 13.33 & Caryophyllene oxide \\
\hline 4 & 13.38 & Spiro[4,5]decan-7-one,1,8-dimethyl-8,9-epoxy-4-isopropyl- \\
\hline 5 & 14.62 & 2,6,10-trimethylundec-9-enoic acid \\
\hline 6 & 15.63 & Perhydrocyclopropa[e]azulene-4,5,6-triol,1,1,4,6-tetramethyl \\
\hline 7 & 17.1 & 4,5,7-trihydroxy isoflavone \\
\hline 8 & 17.55 & 1,5,9-Cyclotetradecatriene,1,5,9-trimethyl-12-(1-methylethenyl)- \\
\hline 9 & 18.8 & phytol \\
\hline 10 & 18.83 & 4H-1-Benzopyran-4-one,5,7-dihydroxy-2-\{2-methoxyphenyl $\}-$ \\
\hline 11 & 21.12 & Androst-5-en-17-one,3-hydroxy-16-\{1-methylethylidene $\}-,\{3 a\}-$ \\
\hline 12 & 21.77 & Pyrano[4,3-b]benzopyran-1,9-dione, 5a-methoxt-9a-methyl-3-(1-propenyl)perhydro- \\
\hline 13 & 23.32 & 1-[3,3-Dimethyl-2-(3-methyl-buta-1,3-dienyl)-cyclopentyl]-2-hydroxy-ethanone \\
\hline 14 & 24.23 & Corynan-17ol,18,19-didehydro-10-methoxy,acetate \\
\hline 15 & 25.67 & $\begin{array}{c}\text { 4-Piperidineacetic acid,1-acetyl-5-ethyl-2-[3-\{2-hydroxyethyl }\}-1 \mathrm{H}-\text {-indol-2-yl }]-\mathrm{a}-\mathrm{methyl}-\text {,methyl } \\
\text { ester }\end{array}$ \\
\hline 16 & 26.22 & 5a-Pregnane-12,20-dione \\
\hline 17 & 29.07 & Pregnan-20-one, 5,6-epoxy-3,17-dihydroxy-16-methyl-(3a,5a,6a,16a)- \\
\hline 18 & 31.03 & 3-Beta-acetoxy-6-nitroandrost-5-en-17-one \\
\hline 19 & 32.68 & Pregnan-20-one, 3-(acetyloxy)-17-hydroxy-, (3a,5a)- \\
\hline
\end{tabular}

Table 1:- Supposed Compounds by GC-MS Library with Retention time

\section{B. Active site Identification}

After the construction of the final model, BCL-2 binding sites were selected by comprising template structure and model construction with the CASTP server and presented in Figure 2. The domain uses the SPDBV system; found that the second structure is highly conserved in final refined model of Bcl-2. 


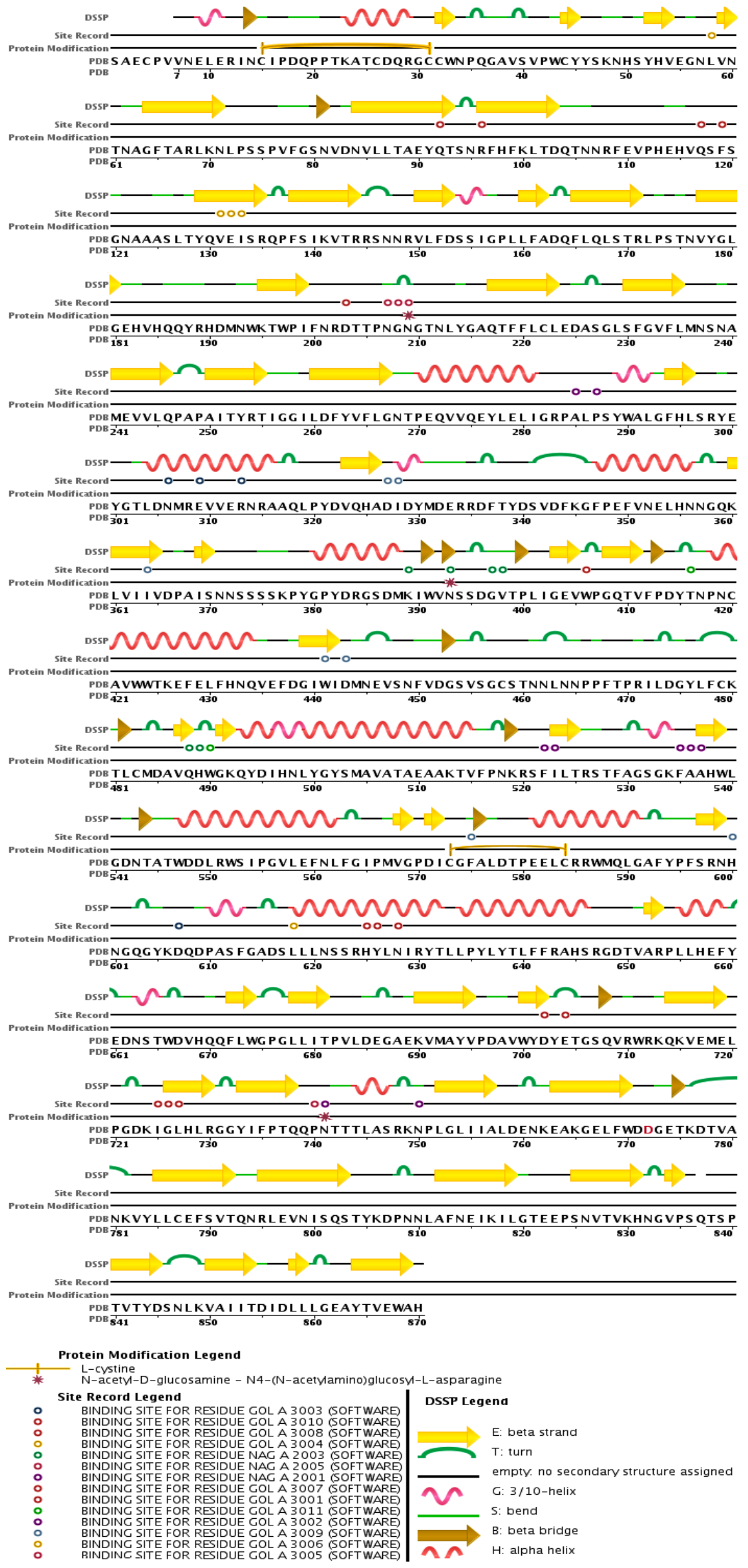

Fig 2:- The possible binding sites of BCL-2 


\section{Docking of inhibitors with the active site}

GOLD 3.0.1 based on genetic algorithm was used for Bcl-2 docking studies of GC-MS identified chemical structures. This program produce a group of disparate rigid body formalization (poses) for each compound conformer in the binding pocket and then transmits every compound across a pessimistic image of the binding site. Poses engaging with this 'bump map' are abolished. Poses outlive the bump test are then recorded and rated with a Gaussian shape function. We expounded the binding packet applying a ligand-free protein structure and a box that encloses the binding site. It was described by expanding the size of the cocrystalized ligand by $4 \mathrm{~A}^{\circ}$. This measure was appraised suitable to accept, for example, larger compounds than those which cocrystalized to fit into the binding site. One distinctive pose for each of the high-score chemicals was maintained in the following steps. Chemicals used to set up 3D-converted dockets with SILVER. In this set, a protein-compatible substrate is added. The incorporation of a leading inhibitor with an active protein site has shown molecule activity in protein function.

\section{Docking pictures}
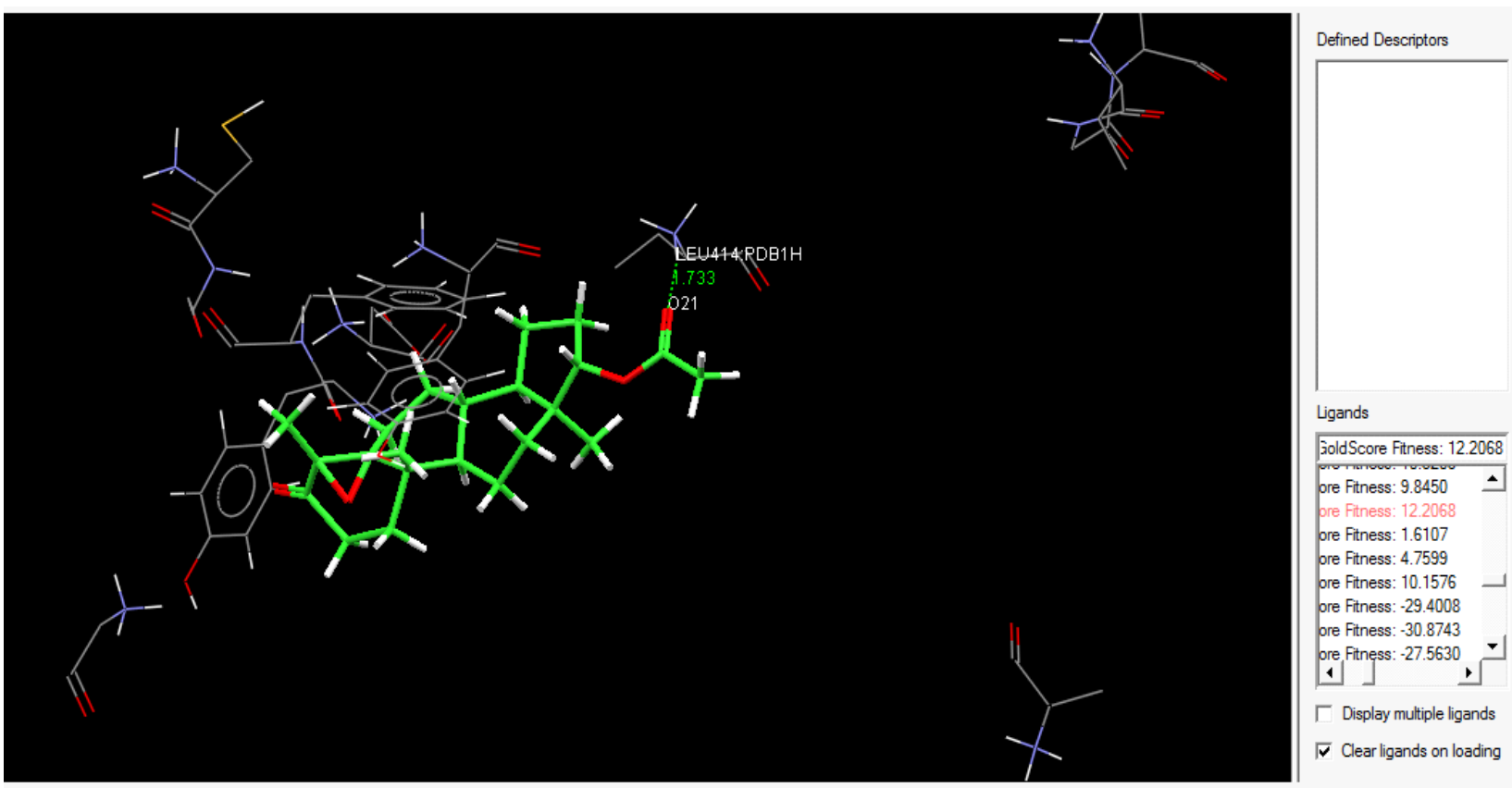

Fig 3:- Docking image for 4,5,7-trihydroxy isoflavone
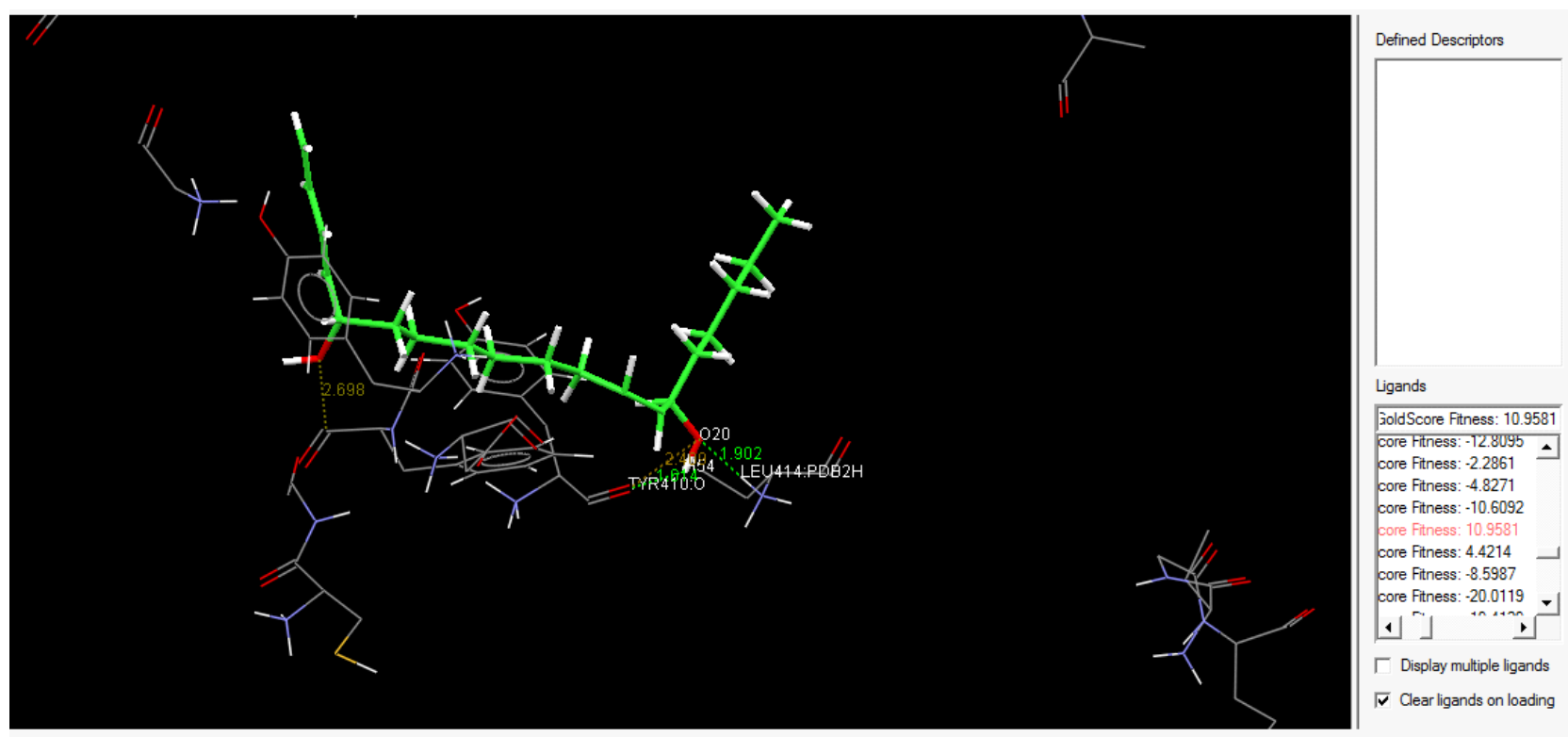

Fig 4:- Docking image for 1,5,9-Cyclotetradecatriene,1,5,9-trimethyl-12-(1-methylethenyl)- 


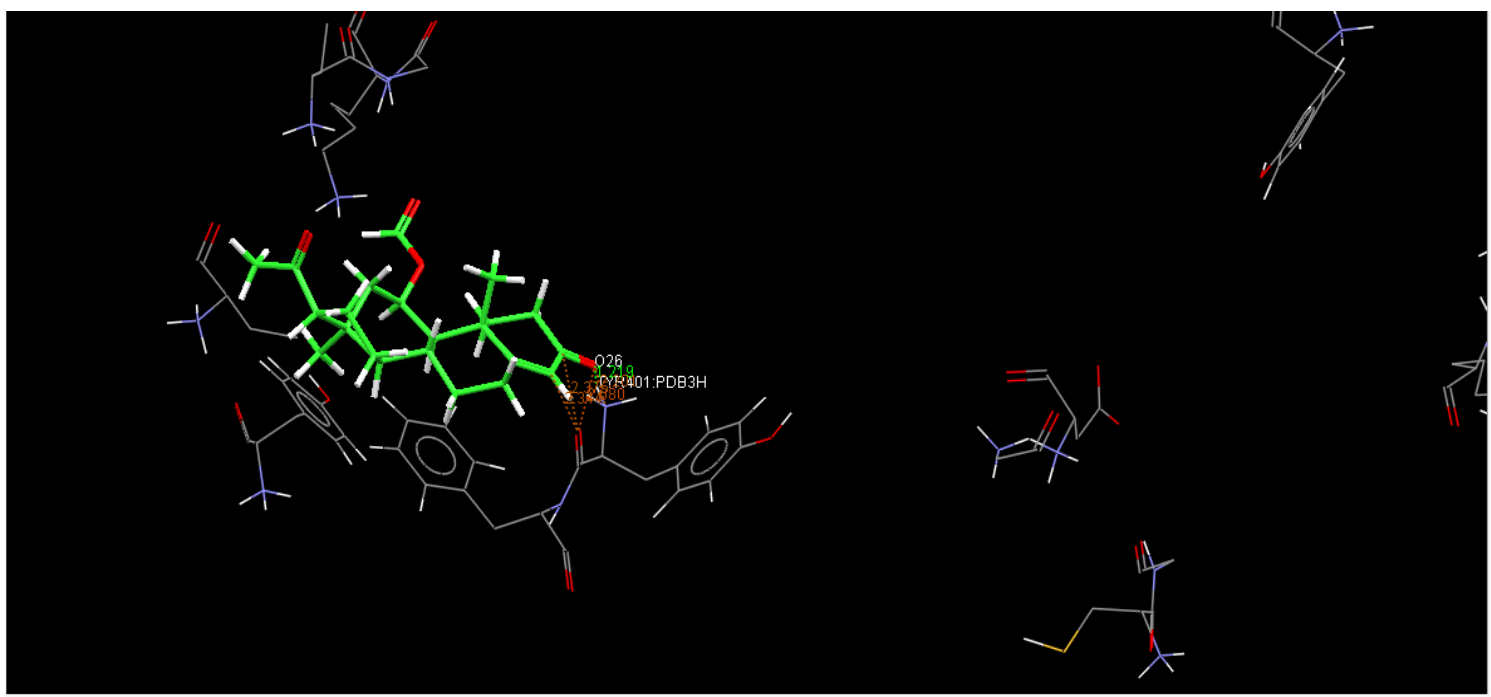

Fig 5:- Docking image for 4H-1-Benzopyran-4-one,5,7-dihydroxy-2-\{2-methoxyphenyl $\}$ -
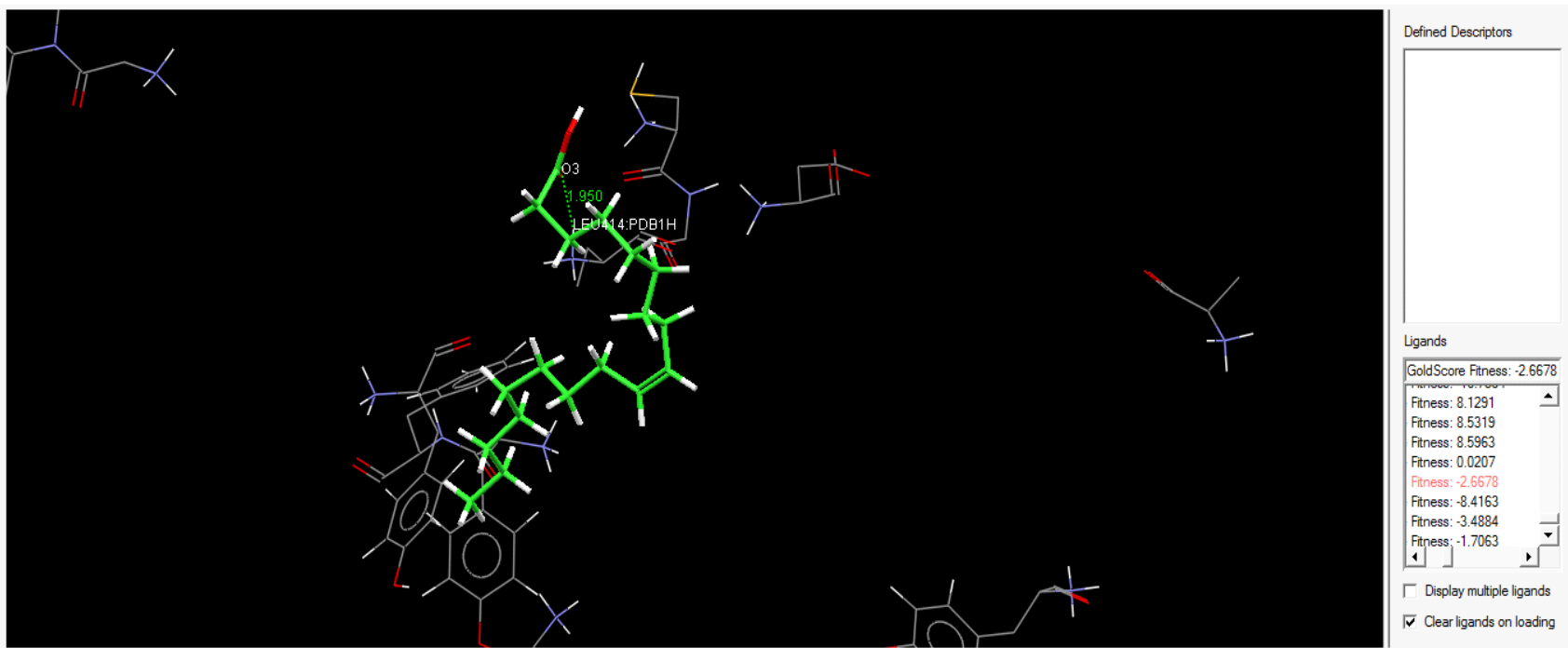

Fig 6:- Docking image for Androst-5-en-17-one,3-hydroxy-16-\{1-methylethylidene $\}-,\{3 a\}-$
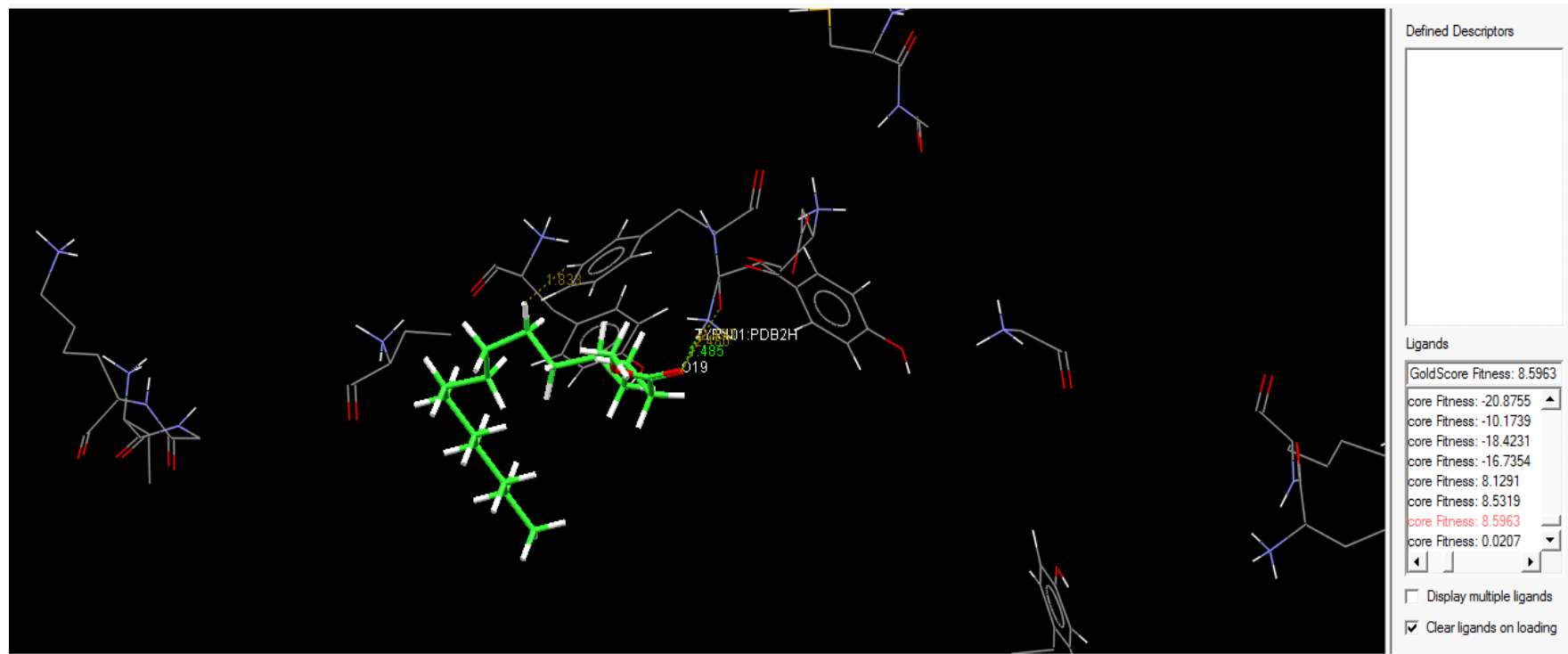

Fig 7:- Docking image for Pyrano[4,3-b]benzopyran-1,9-dione, 5a-methoxt-9a-methyl-3-(1-propenyl)perhydro- 

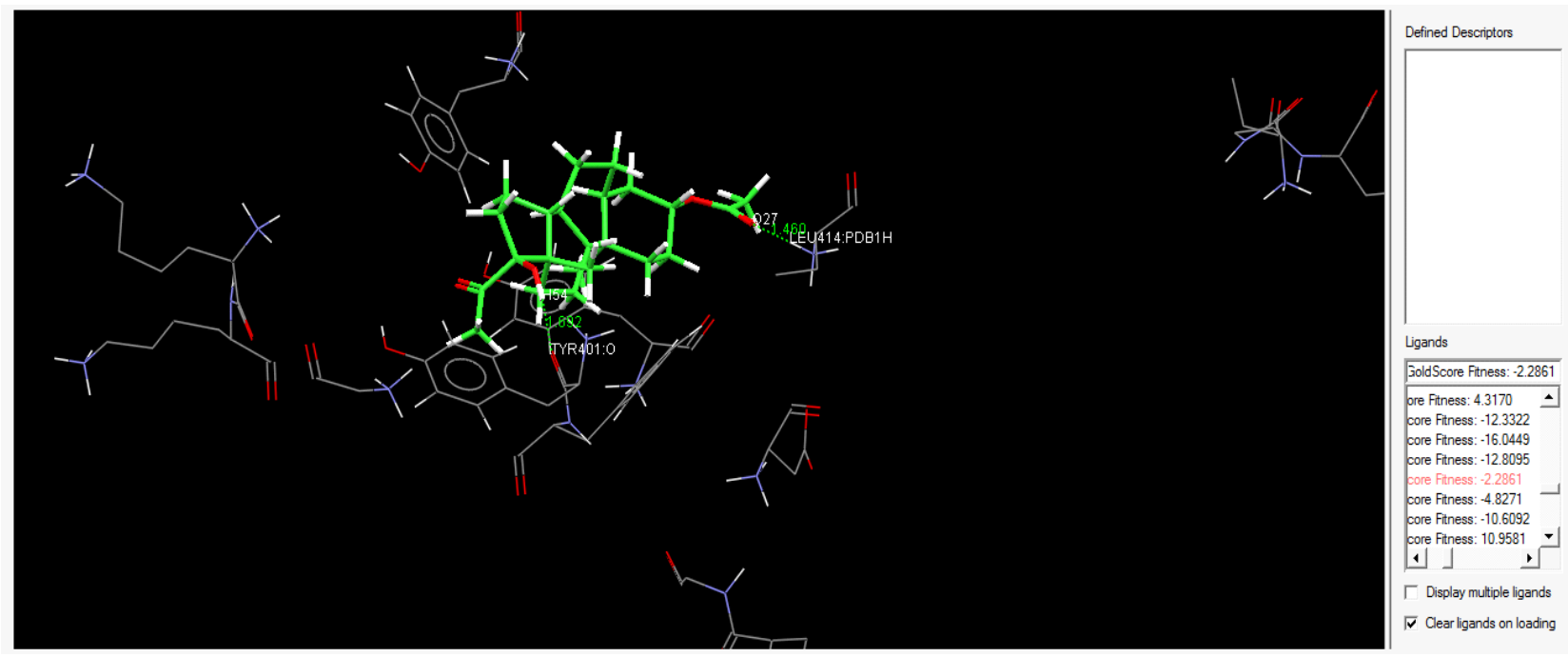

Fig 8:- Docking image for Corynan-17ol,18,19-didehydro-10-methoxy,acetate
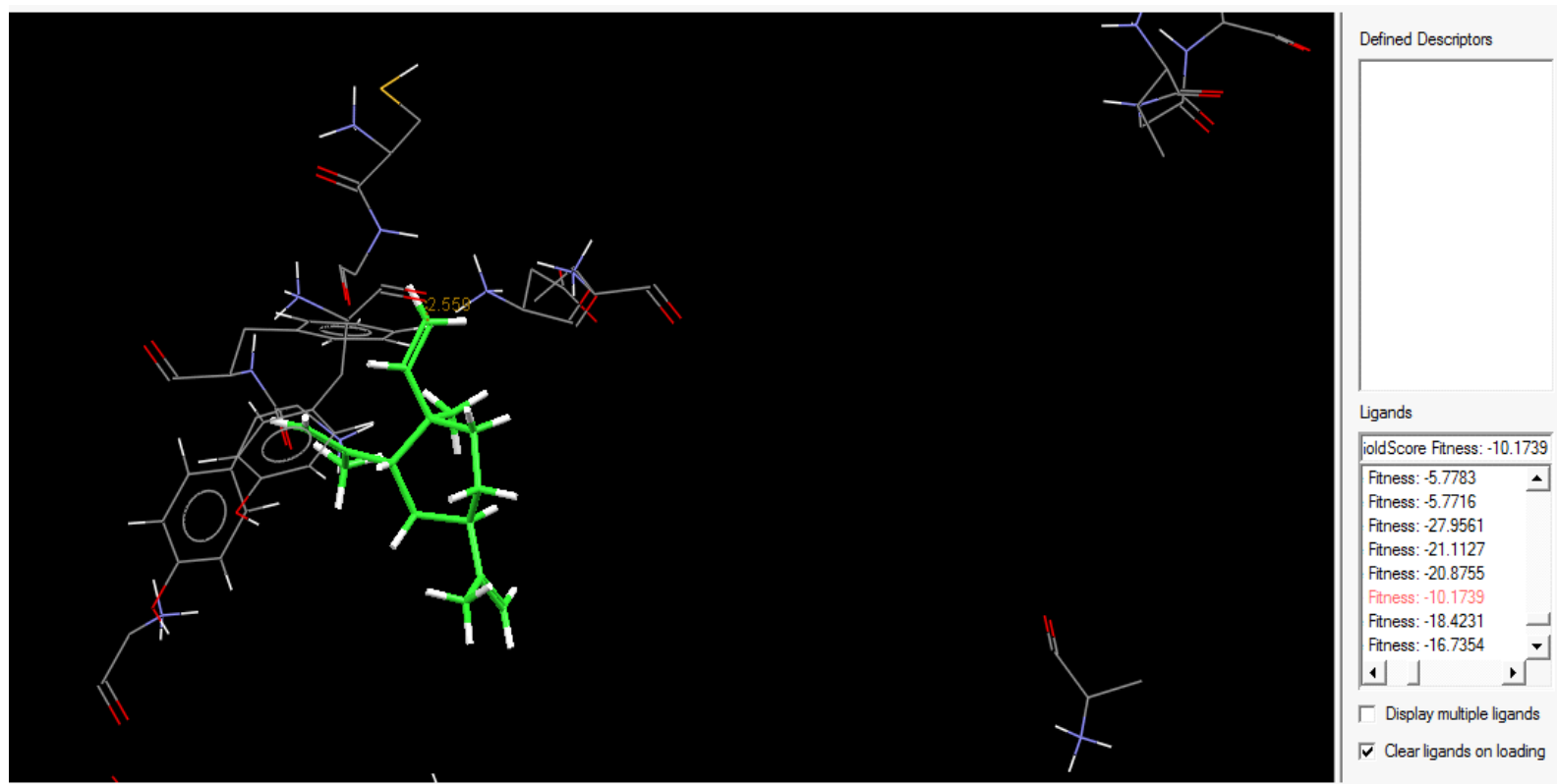

Fig 9:- Docking image for 4-Piperidineacetic acid,1-acetyl-5-ethyl-2-[3-\{2-hydroxyethyl\}-1H-indol-2-yl]-a-methyl-,methyl ester
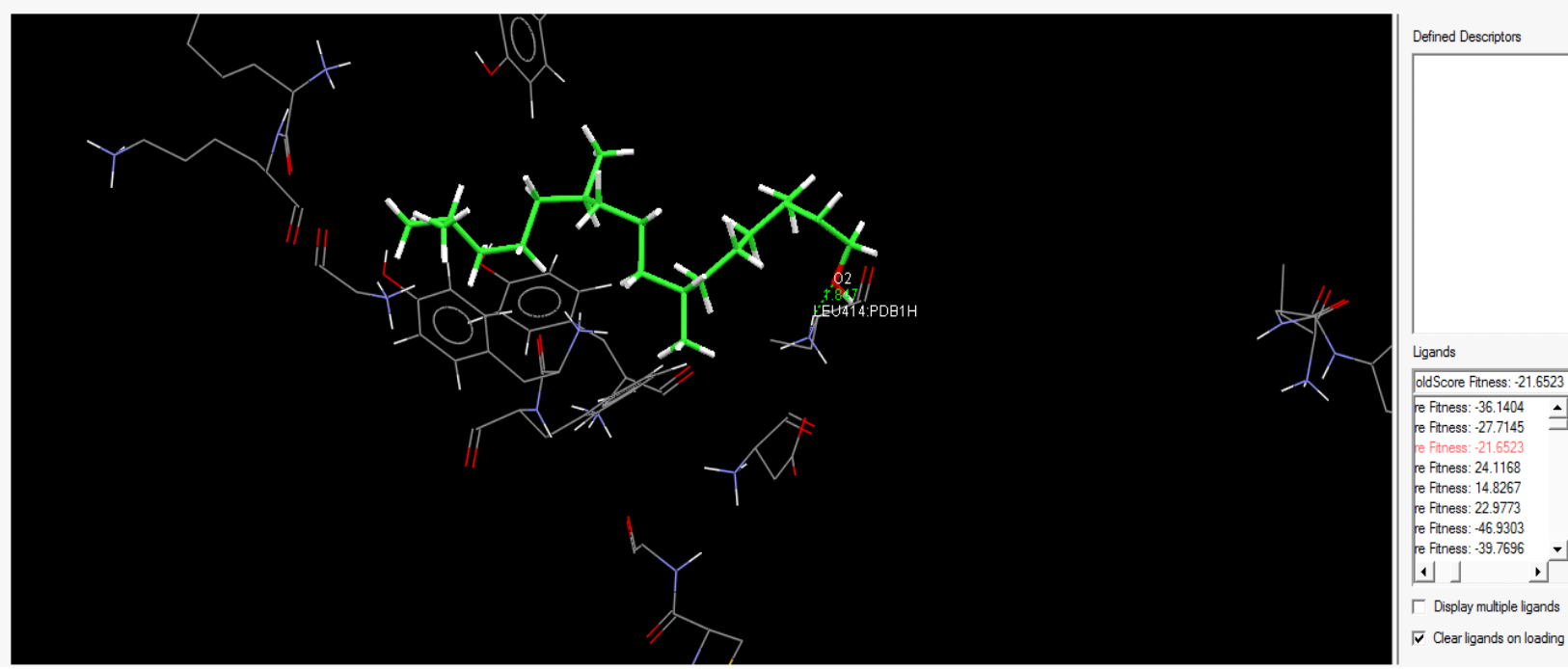

Fig 10:- Docking image for 5a-Pregnane-12,20-dione 


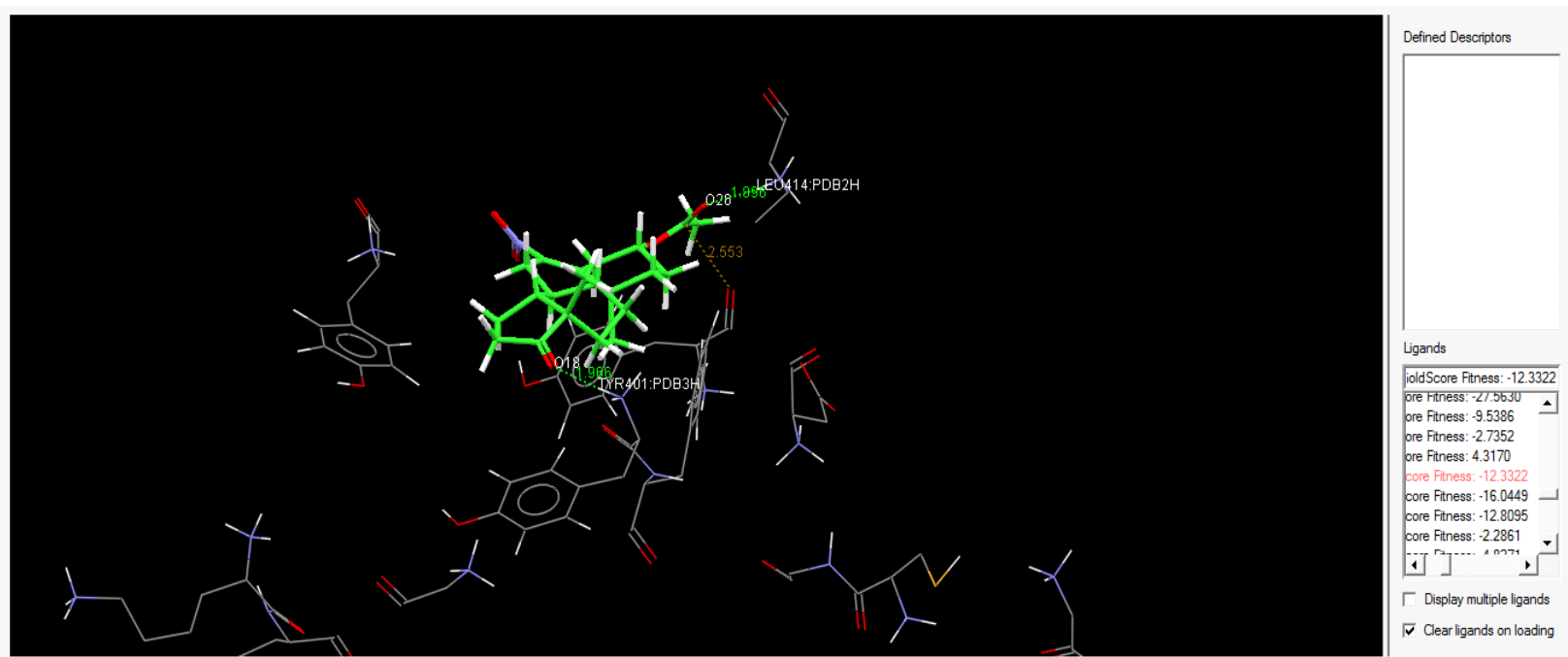

Fig 11:- Docking image for Pregnan-20-one, 5,6-epoxy-3,17-dihydroxy-16-methyl-(3a,5a,6a,16a)-

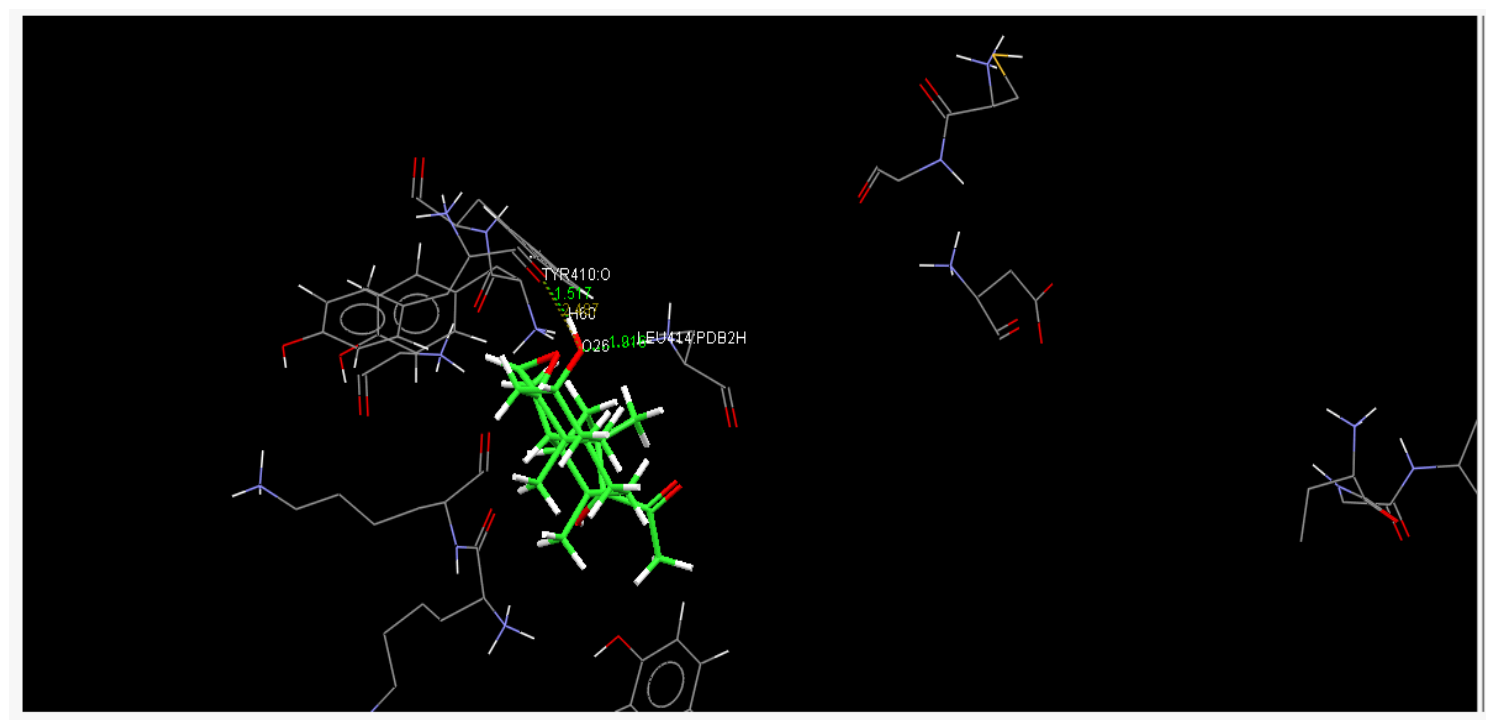

Defined Descriptors

Fig 12:- Docking image for 3-Beta-acetoxy-6-nitroandrost-5-en-17-one

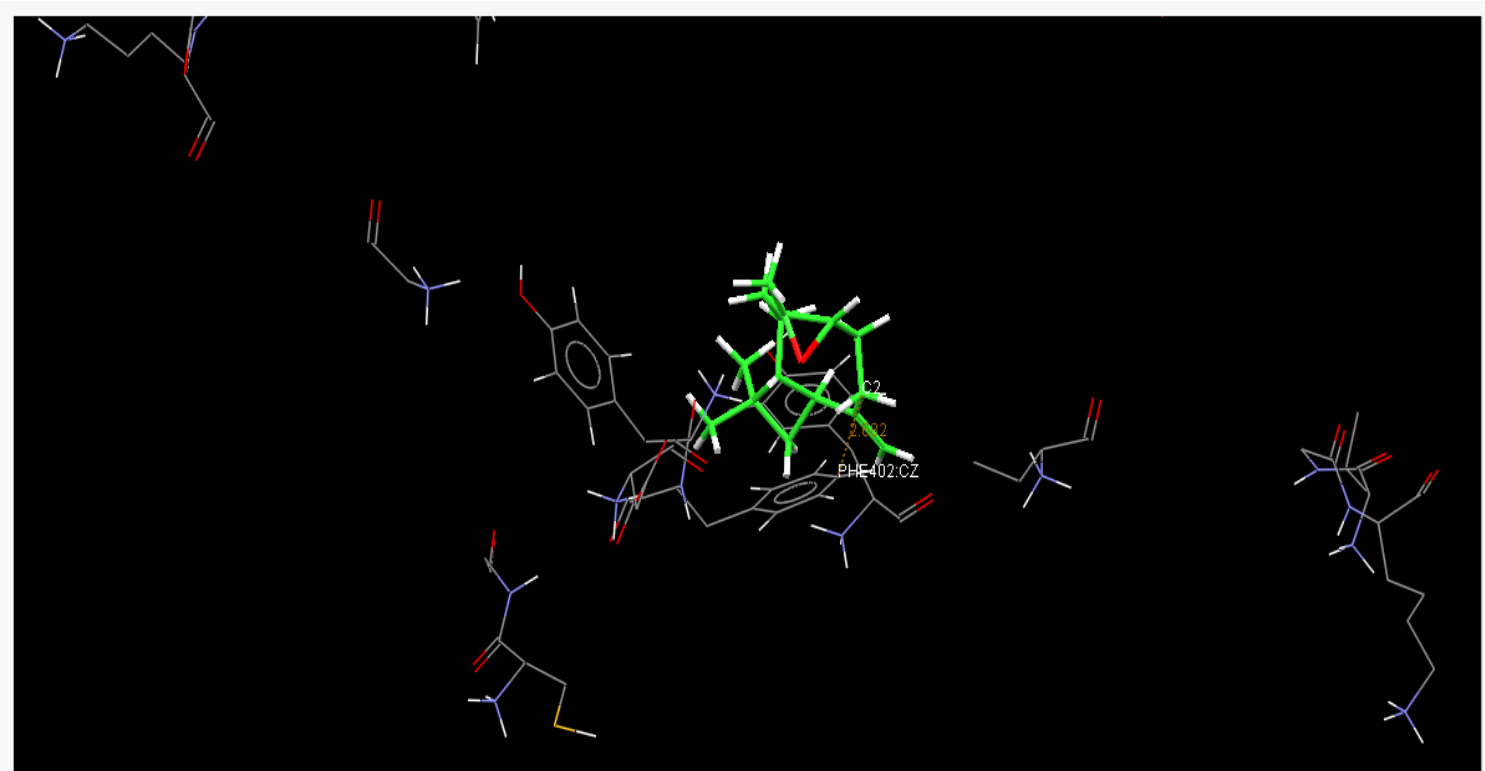




\section{CONCLUSION}

The phytocompounds identified by gas chromatographic studies and structural integration were performed by Mass spectrum analysis were docked into BCL-2 for their anti-cancer activity. Among these docked phytocompounds, 4,5,7-trihydroxy isoflavone showed the highest docking value for BCL-2 inhibitor.

\section{REFERENCES}

[1]. L Goldman, A Schafer, "Biology of cancer. In: Goldman's Cecil Medicine", 23rd ed., USA: Elsevier; 2007. p. 187.

[2]. M. R. Stratton, P. J. Campbell, P. A. Futreal, " The cancer genome", Nature. 2009, 458(7239), 719-724.

[3]. D. Johansen, T.

Stocks, H. Jonsson, B. Lindkvist, T. Björge, H. Conci n, M. Almquist, C.

Häggström, A. Engeland, H. Ulmer, G. Hallmans, R. Selmer, G. Nagel, S. Tretli, P. Stattin, J. Manjer, "Metabolic Factors and the Risk of Pancreatic Cancer: A Prospective Analysis of almost 580,000 Men and Women in the Metabolic Syndrome and Cancer Project", Cancer Epidemiol Biomarkers Prev, 2010, 19 (9), 2307-2317.

[4]. J. Kruk, "Lifetime physical activity and the risk of breast cancer: a case-control study", Cancer Detect Prev., 2007, 31, 18-28.

[5]. M.A. Moyad, P.R. Carroll, "Lifestyle recommendations to prevent prostate cancer, part II: time to redirect our attention?" Urol Clin North Am., 2004, 31, 301-11.

[6]. R Montesano, J. Hall, "Environmental causes of human cancers" Eur J Cancer, 2001,37, S67-87.

[7]. GH Lyman, "Risk factors for cancer", Prim Care, 1992, 19, 465-79.

[8]. H. O. Adami, N. E. Day, D. Trichopoulos, W. C. Willett, Primary and Secondary prevention in the reduction of cancer morbidity and mortality, Eur. J. Cancer, 2001, 37 (8), 118-127.

[9]. J.M. Adams, S. Cory "The Bcl-2 apoptotic switch in cancer development and therapy", Oncogene, 2007, 26, 1324-1337.

[10]. A.J. García-Sáez "The secrets of the Bcl-2 family", Cell Death Differ, 2012, 19, 1733-1740.

[11]. M.C. Wei, W.X. Zong, E.H. Cheng, "Proapoptotic BAX and BAK: a requisite gateway to mitochondrial dysfunction and death" Science, 2001, 292, 727-730.

[12]. T. Kuwana, L. Bouchier-Hayes, J.E. Chipuk, "BH3 domains of $\mathrm{BH} 3$-only proteins differentially regulate Bax-mediated mitochondrial membrane permeabilization both directly and indirectly", Mol Cell, 2005, 17, 525-535.

[13]. F. Llambi, T. Moldoveanu, SWG Tait, "A unified model of mammalian BCL-2 protein family interactions at the mitochondria", Mol Cell, 2011, 44,517-531.

[14]. V. Kirkin, S. Joos, M. Zörnig, "The role of Bcl-2 family members in tumorigenesis", Biochim Biophys Acta Mol Cell Res, 2004; 1644, 229-249.
[15]. M.D. Wendt "Discovery of ABT-263, a Bcl-family protein inhibitor: observations on targeting a large protein-protein interaction", Expert Opin Drug Discov, 2008, 3, 1123-1143.

[16]. I.J. Enyedy, Y. Huang, Y.Q. Long, "Discovery of smallmolecule inhibitors of Bcl-2 through structurebased computer screening", J Med Chem, 2001, 44, 4313-4324.

[17]. J-L. Wang, D. Liu, Z-J. Zhang, "Structure-based discovery of an organic compound that binds Bcl-2 protein and induces apoptosis of tumor cells" Proc Natl Acad Sci, 2000, 97, 7124-7129.

[18]. Y. Harazono, K. Nakajima, A. Raz, "Why anti-Bcl-2 clinical trials fail: a solution" Cancer Metastasis Rev, 2014, 33,285-294.

[19]. H. Wu, Q. Dai, M.J. Shrubsole, R.M. Ness, D. Schlundt, W.E. Smalley, H. Chen, M. Li, Y. Shyr, "Fruit and vegetable intakes are associated with lower risk of colorectal adenomas", J Nutr., 2009,139, 340 4.

[20]. N. Kurahashi, M. Inoue, M. Iwasaki, Y. Tanaka, M. Mizokami, S. Tsugane, "JPHC Study Group. Vegetable, fruit and antioxidant nutrient consumption and subsequent risk of hepatocellular carcinoma: a prospective cohort study in Japan" Br J Cancer" 2009,100, 181-4.

[21]. N.M.R. Mohamad, M.A. Shahkla, H.A. Mohmad, A.R. Siti, M.Z. Razauden, Y. Harisun, "Molecular docking Studies of bioactive compounds from Annona muricata Linnas Potential inhibitors for BcL-2,BcL-W and McL-1 antiapoptotic proteins", Apoptosis, 2018,23(1), 27-40. 